\section{Southern oscillation index and atmospheric carbon dioxide}

BACASTOW $^{1}$ claims that the Southern Oscillation (SO) modulates atmospheric carbon dioxide, which may be true, but was not proven by his article.

Bacastow compared a SO index with both carbon dioxide concentrations and its time derivative. In his Fig. 1 carbon dioxide concentrations were smoothed in an unspecified manner. Taking the derivative is equivalent to applying a high pass filter to the data and results therefore depend on the original smoothing. With different forms of smoothing applied to each series the phase relations will be affected.

The period of data used in the study was from 1958 to 1974 , which includes the period 1960-1965 when the SO was not operating effectively. Trenberth ${ }^{2}$ shows that, in the early 1960s, the correlations of pressure between Easter Island and Darwin-required by the SO mechanism to be negative-were in fact positive. He further shows that the SO operates only on a time scale of $2-10 \mathrm{yr}$ and mainly in the 3-6-yr range. Marked quasi-biennial fluctuations occur at Darwin, but not Apia, Tahiti, or Easter Island in the South Pacific. The quasibiennial oscillation and the SO are not apparently the same thing, although they may interact at times. Furthermore, lags of up to $1 \mathrm{yr}$ are involved in the opposite changes at Darwin and Easter Island ${ }^{2}$.

Further consideration should therefore be given to the choice of a SO index. Trenberth suggests that a simple index involving only Darwin and Tahiti would

\begin{tabular}{lccccc}
\hline \multicolumn{7}{c}{ Table 1 Southern Oscillation index correlation with $\mathrm{CO}_{2}$ data } \\
\hline $\begin{array}{l}\text { Derivative } \\
\text { anomaly }\end{array}$ & SO index & Smoothing & $\begin{array}{c}\text { Correlation } \\
\text { maximum }\end{array}$ & $\begin{array}{c}\text { Anomaly lag } \\
\text { (month) }\end{array}$ & $\begin{array}{c}\text { Standard } \\
\text { deviation }\end{array}$ \\
South Pole & $P_{E A S}-P_{\text {DAR }}$ & 12 month running mean & -0.64 & 6 & 0.34 \\
Mauna Loa & $P_{\mathrm{EAS}}-P_{\text {DAR }}$ & 12 month running mean & -0.55 & $2 \frac{1}{2}$ & 0.28 \\
South Pole & $P_{\mathrm{UAS}}-P_{\mathrm{DAR}}$ & Spline & -0.70 & 6 & 0.36 \\
Mauna Loa & $P_{\mathrm{EAS}}-P_{\mathrm{DAR}}$ & Spline & -0.56 & $2 \frac{1}{2}$ & 0.31 \\
South Pole & SO1 & 3 month running mean & -0.60 & 4 & 0.26 \\
South Pole & SO2 & 3 month running mean & -0.59 & 4 & 0.24 \\
\hline
\end{tabular}

$P_{\mathrm{EAS}}$ and $P_{\mathrm{DAR}}$, seasonal pressure anomalies at Easter Island and Darwin respectively. be best since these stations have the highest negative correlation $(-0.76$ for yearly values for 1944-73) and are almost exactly out of phase. This could be used to define lag relationships elsewhere. Seasonal, rather than monthly data should be used.

To find such an index, we note that an exact inverse correlation between Darwin and Tahiti, using their standard deviations gives

$$
P_{\text {Darwin }}=-1.26 P_{\text {Tahiti }}
$$

where $P$ is the seasonal pressure anomaly. Since part of the mass compensation from the Indonesian centre of action of the SO occurs south of Australia and New Zealand as well as in the South Pacific $^{3}$, greater weight should be given to the pressure at Darwin in a SO index (see Fig. 6 of ref. 3). A suitable weighted index, based on covariances, is

$$
\mathrm{SO} 1=P_{\text {Tahiti }}-1.2 P_{\text {Darwin }}
$$

As only two stations are included, some noise would be present, but is measured by

$$
\mathrm{SON}=1.26 P_{\text {Tahiti }}+P_{\text {Darwin }}
$$

which from (1), has a zero value if the SO is operating.

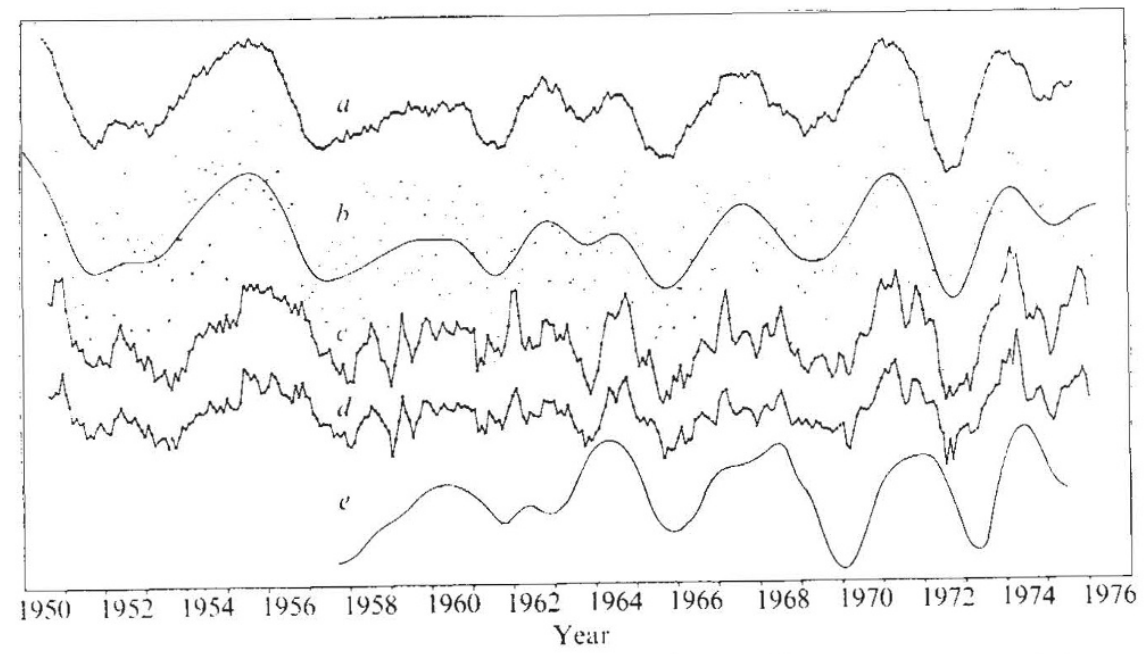

Fig. 1 Southern Oscillation indices. $a$, Differences in monthly average pressure between Easter Island and Darwin, Australia, smoothed by a 12-month running mean (which also removes the seasonal effect). $b$, Pressure differences above with the seasonal effect removed. The curve is a spline obtained by the procedure used to find the $\mathrm{CO}_{2}$ anomalies, and, accordingly, the stiffness of the spline was adjusted by eye. The seasonal effects were calculated by an average over identical months of the difference between the pressures and the spline. $c$, SO1. The seasonal effects at Tahiti and Darwin were determined by an average over identical months of the monthly average pressure records (since 1950) and removed from each record by subtraction. Each record was then smoothed by a 3 -month running mean and SO1 calculated. $d, \mathrm{SO} 2$. $e$, Inverted time derivative of the South Pole anomaly, for comparison.
An index that combines (2) and (3) is

$$
\mathrm{SO} 2=\frac{P_{\text {Tahiti }}-1.2 P_{\text {Darwin }}}{1 \cdot|\mathrm{SON}|}
$$

I suggest that this index may be more useful than any previously used.

\section{K. E. Trenberth}

New Zealand Meteorological Service,

PO Box 722,

Wellington, New Zealand

1 Bacastow R. B. Nature 261, 116-118 (1976). (1976).

3 Kidson, J. W. Mon. Wea. Rev. 103, 187-196 (1975).

BACASTOW REPLIES-Trenberth is correct in pointing out that different filtering of two time series will, in general, affect their correlation-time lag relationship. I do not believe, however, that this consideration is important in judging the existence of a connection between the Southern Oscillation (SO) and the atmospheric $\mathrm{CO}_{2}$ level. If a Southern Oscillation Index is generated by smoothing the Easter Island-Darwin, Australia, pressure differences by the procedure applied to the $\mathrm{CO}_{2}$ data, the cross correlation functions of this index with the time derivatives of the $\mathrm{CO}_{2}$ anomalies (see Table 1 for summary) are essentially the same as found for these pressure differences smoothed by a 12 month running mean.

The mechanism behind the SO is poorly understood, so the best index to represent it is unclear. The indices suggested by Trenberth (calculated from data in ref. 1) are qualitatively quite similar to the Easter Island-Darwin Index, except for the obvious difference in degree of smoothing (Fig. 1). Pressure anomalies were smoothed by a 3-month running mean, in accordance with Trenberth's suggestion that seasonal data be used. Cross correlation functions of $\mathrm{SO} 1$ and $\mathrm{SO} 2$ with the $\mathrm{CO}_{2}$ anomaly derivative at the South Pole (Table 1) are very similar to those found for the Easter Island-Darwin Index, except that the lag of the anomaly is about 2 months less relative to the Tahiti-Darwin indices, as would be expected from the analysis of Trenberth ${ }^{2}$.

\section{R. BACASTOW}

Scripps Institution of Oceanography,

University of California, La Jolla, California 92093

1 Mon. clim. Data Wla. (1976).
2 Trenberth, K. E. Q. Jl R. met. Soc. 102, 499-513 